\title{
Threatened Galápagos snails
}

\author{
Guy Coppois and Sue Wells
}

\begin{abstract}
The endemic snails of the Galápagos are threatened-by introduced fire ants, by black rats and by the destruction of the Scalesia forest that is home to many of them. More than $\mathbf{3 0}$ endemic bulimulid snails are now considered endangered there, many of them occurring only in the 10 per cent of the Galápagos that does not have national park status. The problems of protecting them are formidable, and failure would mean the loss not only of individual species, but of a rare opportunity to study speciation in a natural laboratory.
\end{abstract}

The Galápagos Islands need little introduction, particularly to regular readers of Oryx (see Laurie, 1983; Tindle, 1983; Merlen, 1984). However, it is not very often that the invertebrates of this remarkable group of islands are considered. If Darwin was impressed by the now famous Galápagos finch fauna, with 13 endemic species, what would he have thought of the 66 endemic bulimulid snails, of which he collected 16 himself? Although not as striking in appearance, and certainly unlikely to attract as much public attention as birds and giant tortoises, these are equally fascinating. Unfortunately, recent studies have shown that the snails are as vulnerable to man's activities as the vertebrates.

About 90 land snails have been recorded from the Galápagos and several species are still to be described, with possibly many more awaiting discovery. Species of Bulimulus (subgenus Naesiotus), a large genus that is widespread in the southern US, Central and South America, but which is nowhere as diverse as in the Galápagos, dominate the fauna (Coppois and Glowacki, 1983). Since their arrival in the Pleistocene, they have undergone the characteristic startling speciation typical of so many taxonomic groups on the islands. Evolution is almost certainly still occurring, since there is evidence to indicate that species equilibrium in some groups has not been reached (Smith, 1966).
Galápagos bulimulid snails are relatively small, adults ranging in size from 6 to $25 \mathrm{~mm}$, but they show a wide range of morphological characters, perhaps related to different habitats and microclimates (Coppois, 1984). Colours vary from white through dull brown to dark brown or black, sometimes with stripes and often with a spiral band. Ground-living species are duller in colour than arboreal ones, which tend to have paler, polished shells. Shells may be short and globose or long and slender, and the sculpture may be rough or smooth. Variations are also found within species. Bulimulus cavagnaroi, which is restricted to the litter layer in a 300-m wide band from north of Cerro Crocker to Cerro Maternidad on Santa Cruz, shows distinct colour variations in different localities. Most of the population has shells of various shades of brown, but five per cent of the Cerro Maternidad population has white unbanded shells, and a yellow shell is found in part of the Cerro Coralon valley.

Bulimulids are found on most of the major islands in the archipelago, but are absent from Genovesa, Marchena, Baltra, and minor islets such as Guy Fawkes, Enderby, Gardner (near Espanola), Crossman, Cowley, Caldwell, Plaza, and the two northern ones, Wolf and Darwin (Figure 1). As with Darwin's finches, they are generally endemic to one island only, those occurring on several islands often forming Oryx Vol 21 No 4, October 1987 


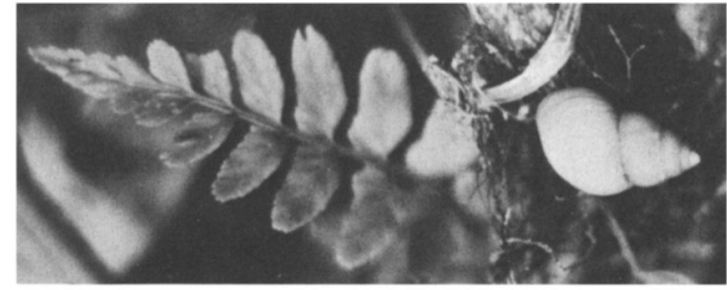

Above: Bulimulus cavagnoroi, with a shell of up to $25 \mathrm{~mm}$, is one of the biggest species of

Galápagos bulimulid snails. Four colour

forms exist; the one shown here is the gilderoyi form, whose range is restricted to a small valley in the highlands of Santa Cruz (Guy Coppois). subspecies. Species inhabiting more than one island in the south-east part of the group are not usually found in the north-west, and vice versa. Thus, B. nux (now extinct apart from two subspecies) was abundant on San Cristobal and Floreana, but did not occur in the north-west, whereas B. jacobi is found on Santa Cruz, Isobela and Santiago. More species are found on the high islands where habitats are more diverse: for example there are 18 on Floreana, 15 on San Cristobal and 24 or 25 on Santa Cruz. The high island of Pinta with only one species is an exception, perhaps because of its isolation. Some

Below: Map of the Galápagos Islands.

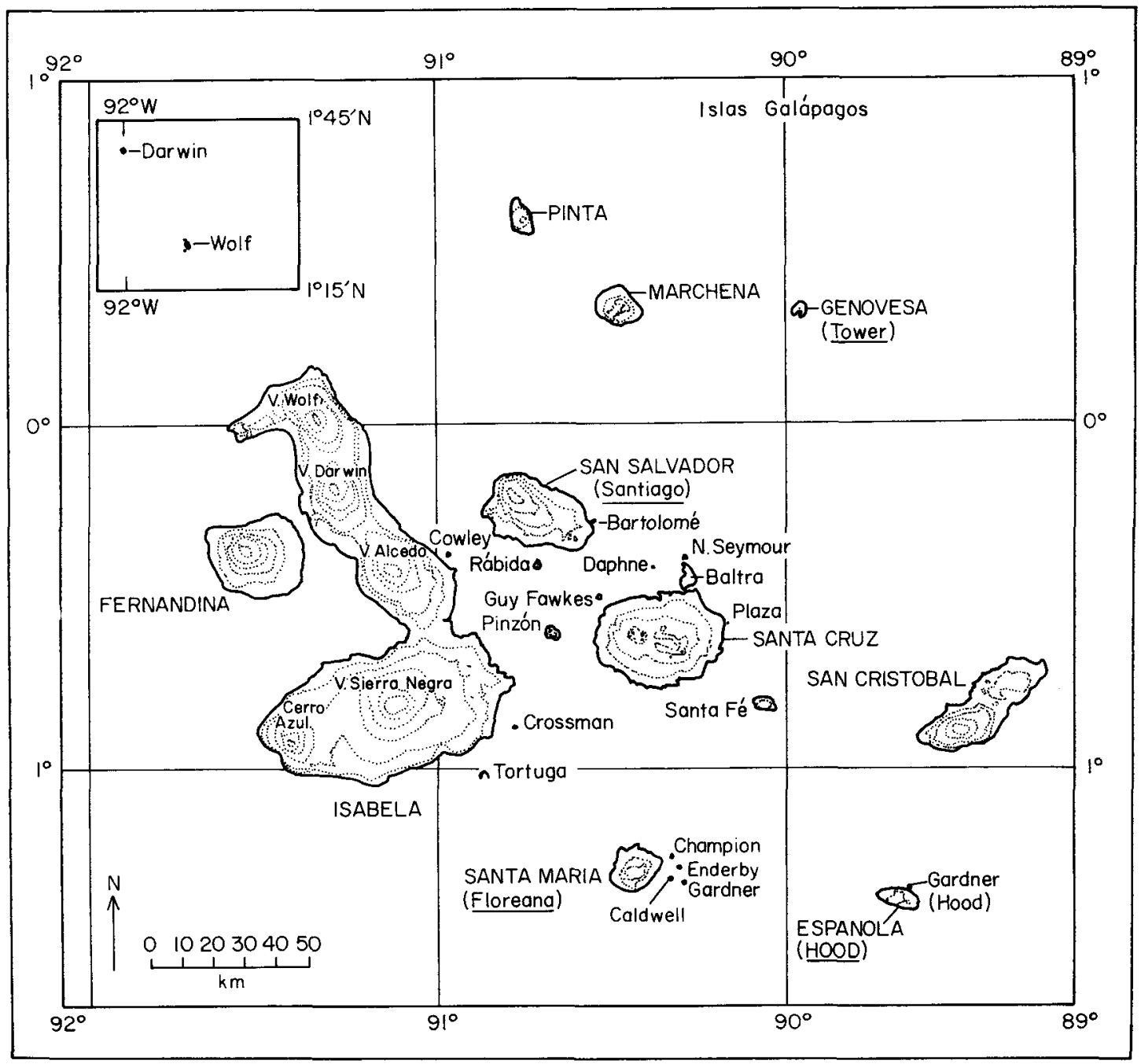



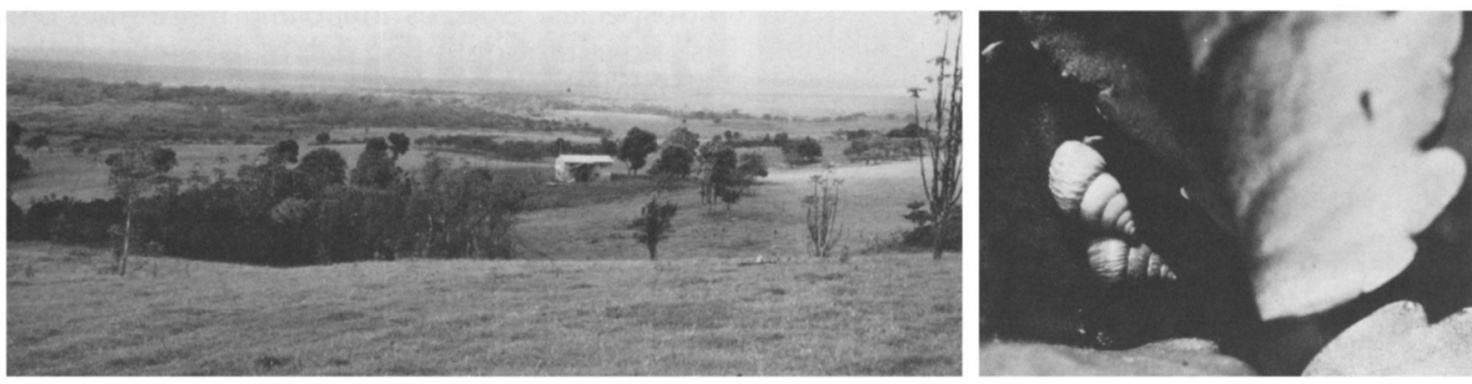

Left: The southern slopes of Santa Cruz, where pasture and cultivations have replaced the endemic Scalesia forests (Guy Coppois).

Right: Bulimulus tortuganus at $300 \mathrm{~m}$ on Sierra Negra, Isabela. Many populations of this species were wiped out by the catastrophic fire that raged on Isabela from late February to June 1985 and devastated part of the volcano's southern slope (Guy Coppois).

species have very wide distributions within an island, such as $B$. ochsneri and $B$. blombergi; others have extraordinarily narrow ranges.

Bulimulids have an unusual ability to adapt to unfavourable environments and are found in desiccated, dusty habitats as well as in moist, vegetation-rich localities. This is particularly noticeable in the Galápagos, where they survive long periods of drought that would be fatal to other species, and has contributed to the spread of this genus to these islands and to their rapid speciation. Nevertheless, some species appear to succumb to these periods of drought, such as $B$. duncanus, which has been extinct since the end of the last century, no live specimens ever having been collected. The drought of 1973 and 1974 had a noticeable impact on many species inhabiting the highlands of Santa Cruz, and, for example, live snails have rarely been found north of Cerro Puntudo since then.

The snails also suffered during the abnormal El Niño of $1982 / 83$, which had a profound effect on much of the wildlife of the Galápagos (Merlen, 1984; Robinson and del Pino, 1985). Between December and July the rainfall was 10 times higher than the average over the preceding 15 years. Although this benfited snails inhabiting the arid zone, the native Scalesia forest was badly damaged, with rotting trees falling to expose the herb and shrub layer. Unfortunately 1984 and 1985 were unusually hot and many forest bulimulid populations died through exposure. It is expected that it will take at least a decade before the forest returns to its previous form (Coppois, in press).

238
However, the greatest threat to the snails is from man. The impact on the snails of some 20,000 tourists a year is negligible, but the resident population has increased from 3500 in 1973 to 10,000 in 1986. San Cristobal and Isabela were colonized first, and Santa Cruz, now with a population of 4500 , was not colonized until the 1920 s, which may account for the comparatively abundant snail densities found there. Much of the human population lives on the coast where tourist activities are based, but there are large areas of farmland in the highlands. For example, forest has been cleared to grow crops, oranges and guajava (now an invasive weed), on Floreana, and pasture for cattle and horses on Santa Cruz. This has eliminated snails in many areas.

Native forest is dominated by the endemic Scalesia pedunculata, which forms a canopy 5$10 \mathrm{~m}$ above ground level, providing permanent shade and high humidity (Hamann, 1978). Despite their adaptability, many bulimulids, such as $B$. alethorhytidus, $B$. ochsneri, $B$ cavagnaroi, $B$. lycodus and $B$. hirsutus, prefer this stable environment, and their distributions are correlated with the now limited areas of this forest (Coppois, 1984). B. nux nuciformis and B. ustulatus are found only in the forest south of Cerro Pajas on Floreana. Although most of the remaining Scalesia forest is within the national park, sizeable patches exist outside. On Santa Cruz, a 1-ha patch on the southern slope at $220 \mathrm{~m}$ at Occidente sheltered a population of $B$. blombergi until 1973 when the bushes surrounding the forest were moved; in less than a year the population had died out. An additional problem is

Oryx Vol 21 No 4, October 1987 
the removal of a local hardwood 'matazarno' Piscidia carthagenensis for fencing and building. The use of fires to clear the vegetation for pasture is now forbidden, but uncontrolled fires have occurred on Santa Cruz in the summit area. Most recently, a major fire lasting from February to July 1985 (Anon., 1985) destroyed a huge area on the Sierra Negra volcano on Isabela and destroyed many arboreal bulimulid populations of $B$. albemarlensis and $B$. tortuganus.

As on many islands, introduced flora and fauna have had a major negative impact on the native species. The introduced little fire ant Wasmannia auropunctata (not to be confused with the true fire ants Solenopsis) has had a major effect on the snails. Eighteen species are believed to be under threat from the ant on Santa Cruz, and a further three on Santiago (see Table 1). Introduced to Santa Cruz less than 50 years ago, the ant is now common on all inhabited islands (Floreana, San Cristobal, Santa Cruz and Isabela) and also on some of the uninhabited islands, usually around landing sites, especially on Santiago. This pest species, probably originating in continental South America, now occurs widely throughout the Neotropics, in parts of the Old World tropics and in the Pacific basin. It appears to be able to out-compete both 'tramp' ants and indigenous species (Lubin,
1984), and is even capable of displacing other arthropods such as spiders and scorpions. Its impact on the snails is still not clear, but in areas with high ant densities bulimulid populations are low or even absent, often only empty shells remaining. Snails have been seen to react to the ants with unco-ordinated movements followed by withdrawal into the shells, but there are few observations of direct attacks. Predation on the juveniles and eggs may in fact be a greater threat as the snails often lay their eggs in empty shells, which are also used by ants as nests.

The black rat Rattus rattus, which had become established in the Galápagos by the time of Darwin's visit in 1835, has caused the extinction of five species of endemic rat, and preys on tortoises, petrel chicks and snails, particularly the larger species (Clark, 1980). The bulimulid population at $\mathrm{El}$ Junco on San Cristobal has been decimated. Predation is less obvious on other islands, but shell remains that have been chewed by rats have been found on Santa Cruz, Santiago and Floreana. Introduced goats have had a major impact on the vegetation, including the Scalesia forest, of at least nine islands (Hamann, 1978). On Pinta, where numbers reached a peak in 1971 , and on Santiago there has been significant destruction of snail habitat. Only a few live

Cerro Pajas, the summit of Floreana. The photograph shows that Scalesia forests still clothe the slopes, but that pasture and introduced Psidium guajava trees have replaced them on adjacent land The dark coloured trees are orange trees (Guy Coppois)

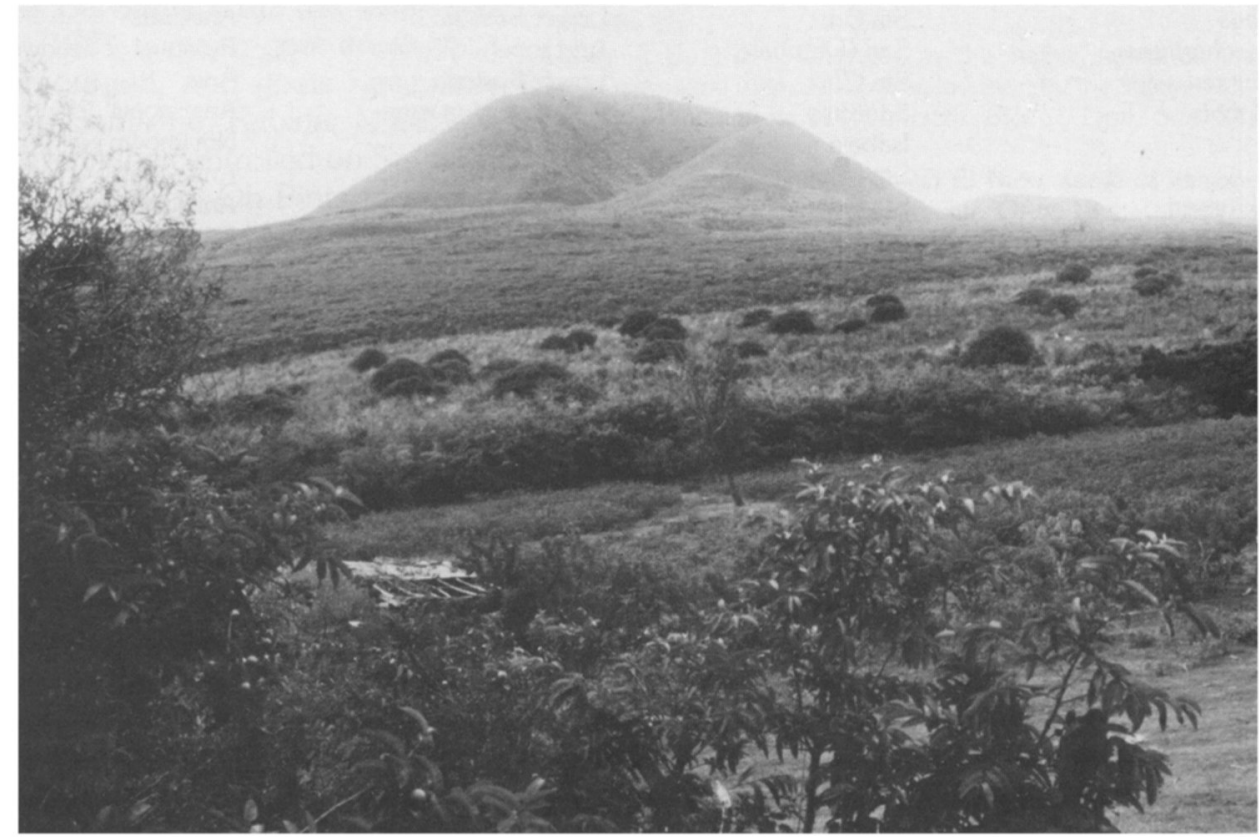


specimens of $B$. darwini were found in 1975 in the Cerro Pelado area on Santiago, and none has been found since. The introduction of various exotic plants has also affected the snails. Where fast-growing introduced Psidium guajava trees have replaced native vegetation, particularly on San Cristobal and Floreana, only empty shells are found.

Over 30 of the endemic bulimulids are now considered to be endangered. In 1959, 90 per cent of the archipelago was declared a national park and is subject to conservation plans devised by the Charles Darwin Research Station and the National Park Authority. Unfortunately, these do not necessarily take the snails into consideration.
In the early 1970s a road was built across Santa Cruz to improve access to the airport on Baltra using sand and gravel collected from sites within the national park, including the Cerro Maternidad, the type locality of $B$. cavagnaroi. The range of this species has been dramatically reduced, and a gravel pit on the slope may alter the microclimate for the remaining population. Ironically, many of the bulimulid snails, such as 11 of the Santa Cruz species, occur only in the 10 per cent outside the national park. Clearly, protection of the Scalesia forest, even outside the national park, is going to be of major importance for the snails.

If the fire ant is having as serious an effect as

Table 1. Endangered Galápagos snails in the genus Bulimulus

\begin{tabular}{|c|c|c|c|}
\hline Name & Distribution & Habitat & Threat \\
\hline adelphus & Sta Cruz & Arid-transition zone & Ants \\
\hline akamatus & Sta Cruz & Arid-transition zone & Ants \\
\hline albemarlensis & Isabela & Highland forest & Rats, habitat destruction \\
\hline alethorhytidus & Sta Cruz & Scalesia forest & Ants \\
\hline amastroides & San Cristobal & Highland forest & Rats, habitat destruction \\
\hline blombergi & Sta Cruz & Scalesia forest & Ants, deforestation \\
\hline calvus & Floreana & Scalesia forest & Rats, deforestation \\
\hline cavagnaroi & Sta Cruz & Scalesia forest, litter & Rats, road construction, fires \\
\hline darwini & Santiago & Highland forest & Rats, goats \\
\hline deridderi & Sta Cruz & Scalesia forest & Ants, rats, fires \\
\hline eos & Sta Cruz & Lower Scalesia & Ants, rats \\
\hline eschariferus & San Cristobal & Arid zone & Removal of deadwood \\
\hline hirsutus & Sta Cruz & Lower Scalesia & Ants \\
\hline \multirow[t]{3}{*}{ jacobi } & Santiago & Arid-transition zone & Ants, goats \\
\hline & Isabela & & Not known \\
\hline & Sta Cruz & Arid-transition zone & Ants, goats \\
\hline krameri & Sta Cruz & Upper transition/Scalesia & Ants, fires \\
\hline lycodus & Sta Cruz & Lower Scalesia & Ants, rats \\
\hline nesioticus & Santiago & Transition zone & Ants, goats \\
\hline nilsodhneri & Sta Cruz & Arid zone & Ants \\
\hline nux nuciformis & Fioreana & Scalesia forest & Rats, exotic trees \\
\hline nux incrassatus & San Cristobal & Scalesia forest & Rats, habitat destruction \\
\hline ochsnen & Sta Cruz & Scalesia forest & Ants, rats, fires \\
\hline reibischi & Sta Cruz & Arid-transition zone & Ants \\
\hline rugiferus & Sta Cruz & Transition zone & Ants \\
\hline saeronius & Sta Cruz & Highland forest & Ants, fires \\
\hline $\begin{array}{l}\text { saeronius } \\
\text { (violet form) }\end{array}$ & Sta Cruz & Scalesia forest & Ants \\
\hline sculpturatus & Santiago & Transition zone & Ants, rats, goats \\
\hline tanneri & Sta Cruz & Arid zone & Ants, deadwood removal \\
\hline tortuganus & Isabela & Highland forest & Rats, habitat destruction \\
\hline tuideroyi & Sta Cruz & Highlands/pampas & Fires \\
\hline unifasciatus & San Cristobal & Scalesia forest & Rats, habitat destruction \\
\hline ustulatus & Floreana & Scalesia forest & Rats, hens, habitat destruction \\
\hline wolfi & Sta Cruz & Arid-transition zone & Ants, rats, deadwood removal \\
\hline Undescribed sp. & Pinta & Arid-transition zone & Goats \\
\hline
\end{tabular}


preliminary data suggest, there is little hope for those species with which it has come into contact. No methods of control have proved successful. In 1975 ants were eliminated from about 2 ha at the landing place and camp site on Santa $\mathrm{Fe}$ by mechanical clearing, but a new invasion was detected at the same site in 1983, in spite of application of strict regulations on the disinfection of food, clothes and equipment (Anon., 1986). This method in any case could not be used in heavily vegetated, larger areas. In the US, extensive research is being carried out on the introduced fire ants, Solenopsis invicta and $S$. richteri, which suggests that a combination of biological and chemical control may be most effective. Until a satisfactory method is found, however, efforts must be directed at preventing the further spread of the ant through the islands.

Major efforts have already been made for the other introduced pest. Control programmes for the black rat are being run by the national park authorities on some islands, concentrating mainly on the petrel colonies on Floreana. Rats were eliminated from Bartholomew but reappeared in 1983, and plans have been discussed for the initiation of a programme on Santa Cruz. As yet there are few satisfactory methods for introduced plants, although 'guajava' has been eliminated from some areas on Santa Cruz (de Vries and Black, 1983). In 1971 a major goat eradication campaign was mounted, and goats have now disappeared from Santa Fe, Rabida, Marchena and Hood, and are being controlled on Santiago (de Vries and Black, 1983). On Pinta, numbers have been reduced to between 40 and 100 , and attempts are being made to remove the remainder.

At present, the Galápagos snails seem to be going the same way as many other Pacific snail faunas: towards extinction. Hawaii has lost 600 of its 1061 endemic snail species, and another 200400 are almost certainly endangered. The endemic Partula snails of Moorea in the Society Islands may be extinct in the wild by the end of the decade, terminating another long-term study of speciation. For many of these species the main hope for the future may lie in captive breeding. In 1896, the malacologist Dall wrote of the Galápagos, 'May it be hoped, therefore, that some one will undertake to make a thorough and Threatened Galápagos snails complete survey of the malacology of these islands before it is too late. The study of the development of specific forms can never be made complete in the Hawaiian Islands, because the sheep and goat have preceded the investigator. There is still a chance to study the problem in the Galápagos Islands and it should not be lost.' Will Dall's worst fears be realised, or can we save this natural laboratory?

\section{References}

Anon. 1985. Drama in the Galápagos. Oryx, 19, 193.

Anon. 1986. News from Academy Bay. Noticias de Galápagos, 43, 5 .

Clark, D.A. 1980. The role of introduced black rats in Galápagos ecosystems. Noticias de Galápagos, 31, 14.

Coppois, G. 1984. Distribution of Bulimulid land snails on the northern slope of Santa Cruz Island. Biol. J. Linn. Soc. 21, 217-227.

Coppois, G. In press. Threatened Galápagos Bulimulid land snails: an update. Proc. 9th Int. Malac. Cong., Edinburgh, September 1986.

Coppois, G. and Glowacki, C. 1983. Bulimulid land snails from the Galápagos. 1. Factor analysis of Santa Cruz Island species. Malacologia 23(2), 209-219.

Dall, W.H. 1896. Insular land shell faunas, especially as illustrated by the data obtained by Dr G. Baur in the Galápagos Islands. Proc. Acad. Nat. Sci. Philadelphia 1896, 395-459.

Hamann, O. 1978. The survival strategies of some threatened Galápagos plants. Noticias de Galápagos, 30, 22-27.

Laurie, A. 1983. Marine iguanas in Galápagos. Oryx, 17, $18-25$.

Lubin, Y.D. 1984. Changes in the native fauna of the Galápagos Islands following invasion by the little red fire ant, Wasmannia auropunctata. Biol. J. Linn. Soc. 21, $229-242$.

Merlen, G. 1984. The 1982-83 El Niño: some of its consequences for Galápagos wildlife. Oryx, 18, 210-214.

Robinson, G. and del Pino, E. 1985. El Niño in the Galápagos Islands: the 1982-83 event. Charles Darwin Foundation for the Galápagos Islands, Quito. Equador.

Smith, A.G. 1966. Land snails of the Galápagos. In The Galápagos (Ed. R. 1. Bowman), Chapter 32. Proc. Symp. Galápagos Int. Sci. Project. University of California Press, Berkeley.

Tindle, R.W. 1983. Galápagos conservation and tourism-11 years on. Oryx, 17, 126-129.

de Vries, T. and Black, J. 1983. Of men, goats and guavaproblems caused by introduced species in the Galápagos. Noticias de Galápagos, 38, 18-21.

This paper is Contribution No. 359 of the Charles Darwin Foundation for the Galápagos Islands.

Guy Coppois, Laboratoire de Zoologie Systématique et d'Ecologie Animale, Université Libre de Bruxelles, 50 av. F. D. Roosevelt, 1050 Bruxelles, Belgium.

Sue Wells, IUCN Conservation Monitoring Centre, 219c Huntingdon Road, Cambridge, CB3 ODL, UK. 